\title{
Biological and Clinical Significance of GATA3 Detected from TCGA Database and FFPE Sample in Bladder Cancer Patients
}

This article was published in the following Dove Press journal: OncoTargets and Therapy

\author{
Chenglu Wang ${ }^{1, *}$ \\ Shuang Yang ${ }^{2, *}$ \\ Lu Jin ${ }^{1, *}$ \\ Guangcheng Dai' \\ Qiu Yao' \\ Han Xiang' \\ Yongsheng Zhang ${ }^{2}$ \\ Xiaolong Liu' \\ Boxin Xue $\mathbb{D}^{\prime}$ \\ 'Department of Urology, Second \\ Affiliated Hospital of Soochow University, \\ Suzhou 215004, People's Republic of \\ China; ${ }^{2}$ Department of Pathology, Second \\ Affiliated Hospital of Soochow University, \\ Suzhou 215004, People's Republic of \\ China
}

*These authors contributed equally to this work
Correspondence: Boxin Xue Second Affiliated Hospital of Soochow University, No. 1055 Sanxiang Road, Suzhou, Jiangsu 215000, People's Republic of China

Tel +86-5 I2-67784I36

Fax +86-5 I 2-68284303

Email xbxurol@।63.com

Xiaolong Liu

Second Affiliated Hospital of Soochow

University, No. 1055 Sanxiang Road,

Suzhou, Jiangsu 215000, People's Republic of China

Tel +86-5 I 2-67784|35

Email liuurol@।63.com
Purpose: The purpose of the present study was to investigate the biological and clinical significance of GATA binding protein 3 (GATA3) in bladder cancer patients.

Patients and Methods: For the detection of the correlation between GATA3 expression and bladder cancer, we downloaded the mRNA expression data from the Cancer Genome Atlas (TCGA) database and conducted immunohistochemistry staining on formalin-fixed paraffin-embedded (FFPE) sample tissues. Then, bladder cancer cell lines were utilized to investigate the potential functions of GATA3 by cell apoptosis, proliferation and cycle assays.

Results: The mRNA data from TCGA database and bladder cancer cell lines suggested that GATA3 mRNA expression was significantly higher compared with normal tissues and cells. Conversely, the Western blot assay revealed that the expression of GATA3 was significantly lower in bladder cancer than normal urothelial cell line. Additionally, we found that overexpression of GATA3 was significantly associated with tumor subtype $(P=0.001$ in TCGA; $P=0.004$ in FFPE tissues), earlier clinical stage $(P<0.001$ in TCGA; $P<0.001$ in FFPE $)$ and lower grade tumor $(P=0.057$ in TCGA; $P=0.002$ in FFPE). Kaplan-Meier analysis and multivariate Cox regression analysis indicated that age $(P<0.001$ in both cohort), clinical stage $(P=0.028$ in TCGA; $P=0.011$ in FFPE), recurrence $(P<0.001)$ and low GATA3 in TCGA cohort $(P=0.035)$ but high GATA3 in FFPE cohort $(P=0.033)$ were independent risk factors for overall survival in patients. The assay to detect potential functions of GATA3 indicated that this biomarker could arrest the cell cycle of G2/M and S phase in T24 cells, and inhibit bladder cancer cells proliferation.

Conclusion: Collectively, our findings identified that GATA3 served as an important prognosis biomarker for bladder cancer patients. However, the mechanism of GATA3 in bladder cancer deserves further studies.

Keywords: GATA3, bladder cancer, expression, prognosis, immunohistochemistry

\section{Introduction}

Bladder cancer, approximately 549,00 new patients and 200,000 deaths worldwide in 2018 , is the 10th most common cancer which has been taking a huge financial burden to all the countries. ${ }^{1,2}$ There are significant sex differences in the incidence and mortality rates of bladder cancer, for men is about 3 to 4 times those of women globally. ${ }^{3}$ However, previous study indicated that women are more common with an advanced disease and poorer clinical prognosis. ${ }^{4}$ Tumors that invading the detrusor muscle are defined as muscle invasive bladder cancer (MIBC). Of these patients, the five-year survival rate is approximately less than $60 \%$ despite aggressive 
treatment and $40 \%$ present metastasis within 2 years. ${ }^{5-7}$ While non-muscle invasive type (NMIBC) often reveals a better prognosis in terms of disease-specific survival, this form of bladder cancer is typically characteristic by its high rate of recurrence after treatment. ${ }^{8}$ According to previous published literature, the development of new therapeutics such as EGFR targeting agents, enfortumab vedotin and checkpoint inhibition had seen a significant advance in the treatment of bladder cancer., ${ }^{4-12}$ Recently, the rapid development of techniques in the area of genome analysis has provided opportunities for personalized medicine using biomarker and target of therapy. Therefore, further confirmation of independent biomarkers is a significant need to precisely predict clinical outcomes, as well as discover effective pathways for molecular target therapy of bladder cancer.

GATA binding protein 3, lof 6 members of zinc finger transcription factor family, was primarily recognized as a $\mathrm{T}$ cell lineage-specific factor and subsequently identified as a critical transcription factor contributing to hematopoiesis, particularly T-cell development and differentiation. $^{13-15}$ It was also discovered that GATA3 plays a significant role in the regulation of proliferation, development and differentiation in various nonhematopoietic tissues and cell types, including mammary epithelial, ${ }^{16-18}$ kidney, $^{19}$ bone, $^{20}$ adipose tissue, ${ }^{21}$ thymocytes, ${ }^{22}$ parathyroid gland, ${ }^{23}$ embryonic articular cartilage, ${ }^{24}$ and hair follicles of the skin. ${ }^{25,26}$ Consistent with the studies mentioned above, it was later shown that overexpression of GATA3 could inhibit breast cancer growth, and GATA3 loss was a biomarker for the independent prediction of poor prognosis in breast cancer patients. $^{27-29}$ GATA3 was initially suggested to be a novel immunohistochemical marker of urothelial differentiation in $2007 .{ }^{30}$ In that research, it was observed that the expression of GATA3 had a significant decrease in urothelial cancers compared with benign urothelium, especially in muscle-invasive or high-grade carcinomas. $^{31}$ Additionally, a simple study carried out by $\mathrm{Li}$ et al showed that GATA3-deficience could inhibit bladder cancer cell migration and invasion. ${ }^{32}$ However, we found that in bladder cancer tissues expression of GATA3 mRNA was higher than normal tissues (TCGA database), while GATA3 protein lower than normal tissues. $^{31}$ To explore the function of clinical significance of GATA3 in bladder cancer, we detected the expression of GATA3 in FFPE sample tissues and performed function assay in bladder cancer cell lines.

\section{Materials and Methods}

\section{Patients and Tissue Samples}

After obtaining the appropriate approval by the institutional review board of The Second Affiliated Hospital of Soochow University, we retrospectively reviewed the information of 107 bladder cancer patients who were admitted from January 2016 to June 2017. All the specimens were retrieved by the tissues obtained from the previous transurethral resection or cystectomy. The original diagnoses were confirmed by a urologic pathologist according to the World Health Organization/International Society of Urological Pathology (WHO/ISUP) ${ }^{33}$ consensus classification of urothelial neoplasms of the urinary bladder. The samples of tissue microarrays were constructed by formalin-fixed, paraffin-embedded bladder cancer specimens.

\section{Bioinformatics Analysis of TCGA Database}

The RNA-seq data of GATA3 expression in urothelial bladder carcinoma patients, comprised of 414 bladder cancer cases and 19 normal tissues, as well as the clinical information were downloaded from the TCGA database. Only the patients including the full clinicopathological information of tumor subtype, tumor histologic grade, tumor pathologic stage, recurrence and overall survival (OS) were included in our analysis. In the end, there were 364 cases of bladder cancer were selected for overall survival analysis in our study.

\section{Cell Lines and Cell Culture}

The human bladder cancer cell lines 5637, T24, RT4 and UMUC3 as well as the human normal urothelial cell line SV-HUC1 were purchased from the American Type Culture Collection (ATCC, Manassas, VA, USA). All cell lines were incubated in complete medium and cultured at $37^{\circ} \mathrm{C}$ in a humidified atmosphere of $5 \% \mathrm{CO}_{2}$. Full-length GATA3 was subcloned into the pcDNA3.1 vector (GenePharma, Suzhou, China) and sequencing was utilized to verify the vector (pcDNA3.1-GATA3). For overexpression of GATA3, Lipofectamine 3000 (Invitrogen; Thermo Fisher Scientific, Inc.) was used to transfect synthesized pcDNA3.1-GATA3 into cells.

\section{RNA Extraction, cDNA Synthesis and RT-qPCR}

Total RNA was extracted from tissues and cells using RNAiso Plus reagent (Takara Bio, Inc., Otsu, Japan). The 
cDNA with $1 \mu \mathrm{g}$ RNA was obtained using a PrimeScript ${ }^{\mathrm{TM}}$ RT reagent kit (Takara Bio, Inc.). Then, with GAPDH as the internal control, qPCR was performed using Premix Ex Taq $^{\mathrm{TM}}$ II (Takara Bio, Inc.) with the Roche Light Cycler 480 Real-Time PCR system. The reverse reaction conditions were as follows: $95^{\circ} \mathrm{C}$ for $1 \mathrm{~min}$, then 40 cycles of $95^{\circ} \mathrm{C}$ for $10 \mathrm{sec}, 60^{\circ} \mathrm{C}$ for $30 \mathrm{sec}$, and $75^{\circ} \mathrm{C}$ for $30 \mathrm{sec}$. Primer sequences are listed as follows: GATA3 (forward, 5'-CAGCCTTCGC TTGGGCTTAA T-3'; reverse, 5'-GA TGGCAGGC TCAGTGATGT C-3') and GAPDH (forward, 5'-AAGGTGAAGG TCGGAGTCAA C-3'; reverse, $5^{\prime}$-GGGGTCATTG ATGGCAACAA TA- $3^{\prime}$ ). The $2^{-\Delta \Delta C q}$ method was utilized to calculate the relative GATA3 expression levels.

\section{Western Blot Analysis}

The proteins of cells were extracted by RIPA buffer (Beyotime, Haimen, China). Protein concentration was measured using BCA Protein Assay (Beyotime, Haimen, China). After loaded and separated by SDS-PAGE, protein was then electrotransferred to PVDF members (Merck Millipore, Darmstadt, Germany). The membranes were further blocked with bovine serum albumin for $1 \mathrm{hr}$, and incubated with primary anti-GATA3 antibody (1:1000, Cell Signalling Technology, Danvers, MA, USA) and antiGAPDH antibody (1:1000, Cell Signalling Technology, Danvers, MA, USA) overnight at $4^{\circ} \mathrm{C}$. After washed with tris buffer solution, the bands were incubated with a secondary antibody for $1 \mathrm{hr}$ and detected by enhanced chemiluminescent assay.

\section{Cell Proliferation Assay}

Cell proliferation was evaluated by applying Cell Counting kit-8 (CCK-8) assay and EdU proliferation assay. Approximately 2000 cells/well were placed into a ninety-six well plate. After cultured for $12 \mathrm{hrs}$, all cells were then transfected with pcDNA3.1-GATA3 or mock. CCK-8 solution was added into wells at designated timepoint. The optical density (OD) value was measured at 490 $\mathrm{nm}$ using a microplate reader (Bio-Rad Laboratories, Inc., Hercules, CA, USA).

The effect of GATA 3 expression on bladder cancer cells was also evaluated by EdU incorporation assay. Briefly, after transfected with pcDNA3.1-GATA3 or mock, cells were then exposed to $50 \mathrm{~nm}$ of $\mathrm{EdU}$ at $37^{\circ} \mathrm{C}$ for $60 \mathrm{~min}$. Furthermore, cells were treated with a 30 -min incubation using $4 \%$ paraformaldehyde at room temperature and with another 30 min by $0.5 \%$ Triton $\mathrm{X}-100$ at room temperature.
Following washing with PBS three times, the cells in all wells were permeabilized with $1 \mathrm{X}$ Apollo reaction cocktail (100 $\mu \mathrm{L} /$ well) for $30 \mathrm{~min}$. The staining of DNA was accomplished by Hoechst 33342 and fluorescence microscopy was utilized to visualize images of each well. Five groups of cells were randomly chosen for each sample. The relative EdU-positive ratio was measured with the mean value of five groups.

\section{Flow Cytometry Detection}

The apoptosis and cell cycle of bladder cancer cells were measured by flow cytometric analyses. As for cell cycle analysis, cells were seeded in 6-well plates at a density of $3 \times 10^{5} /$ well for $24 \mathrm{~h}$ and subsequently transfected with pcDNA3.1-GATA3 or mock. After cultivation for $48 \mathrm{hrs,}$ cells were harvested and washed using phosphate-buffered saline (PBS) twice. The cells were then resuspended using BPS and incubated in the dark after adding the propidium iodide (PI) and RNaseA. The cycles of T24 and UMUC3 cells were measured by flow cytometry machine. As for cell apoptosis analysis, after washing with BPS, apoptotic and necrotic cells were subsequently incubated in cell suspension for 30 mins at room temperature after adding $5 \mu \mathrm{L}$ FITC-Annexin V and $10 \mu \mathrm{L}$ PI. The apoptosis rate was then analyzed using a COULTER $^{\circledR}$ EPICS $^{\circledR}$ XL $^{\text {TM }}$ Flow Cytometer (Beckman Coulter, Inc., Brea, CA, USA).

\section{Immunohistochemistry}

Immunohistochemistry staining was performed at the department of pathology in The Second Affiliated Hospital of Soochow University. The tissue blocks were cut at sections in $5 \mu \mathrm{m}$ thick. After baked for $60 \mathrm{~min}$, paraffin sections were deparaffinized in xylene and ethanol. Deparaffinized sections were then placed in $0.01 \mathrm{~mol} / \mathrm{L}$ sodium citrate buffer, $\mathrm{pH}$ 6.0. The buffer was brought to a boiling temperature and timed for $30 \mathrm{~min}$. Sections were incubated with 3\% $\mathrm{H} 2 \mathrm{O} 2$ for 10 min. After blocked with $10 \%$ goat serum for 15 $\mathrm{min}$, the sections were further incubated with primary antibodies $\left(4^{\circ} \mathrm{C}\right.$, overnight). The sections were then washed three times with PBS and incubated with secondary antibody for $20 \mathrm{~min}$. The sections were stained by DAB Substrate kit and counterstained with hematoxylin. All stains were manually evaluated by one experienced pathologist who was blinded to sample identify. The German Immunoreactive Score was established basing on multiply the staining intensity ( 0 , negative; 1 , weak; 2 , moderate; 3 , strong) by extent of immunoreactive cells $(0 \%=0 ; 1 \sim 10 \%=1 ; 11 \sim 50 \%=2$; $51 \sim 80 \%=3 ; 81 \sim 100 \%=4)$. The interpretation score was 
defined as follows: $0 \sim 1$ ( 0 , negative), $2 \sim 4$ (1+, weakly positive), $6 \sim 8(2+$, moderately positive), $9 \sim 12$ (3+, strongly positive).

\section{Statistical Analysis}

The associations of the expression of GATA3 with clinicopathological data were evaluated by the Chi-squared test or the Mann-Whitney test. The association between various factors and overall survival were calculated by the analyses of univariate and multivariate Cox proportional hazard regression model. Kaplan-Meier analysis and Logrank test were used to plot survival cures. P-value $<0.05$ was considered to be statistically significant. Statistical analyses and graphical presentations were conducted by SPSS 24.0 software and GraphPad Prism Software 6.0.

\section{Result}

\section{The Expression of GATA3 in Human}

\section{Bladder Cancer}

To determine whether GATA3 expression differs between normal tissues and bladder cancer, RNA sequencing data were downloaded from the TCGA database including 364 bladder cancer cases and 19 normal tissues. The result indicated that GATA3 expression was significantly higher in tumor tissues than that in normal (Figure 1A). Furthermore, Western blot analysis was conducted to detect the protein expression of GATA3 in human bladder cancer cell lines (5637, RT4, UMUC3 and T24) as well as human normal urothelial cell line (SV-HUC1). Contrary to expectation, however, the protein level of GATA3 was found significantly lower in bladder cancer cells than that in SV-HUC1 cells (Figure 1B).

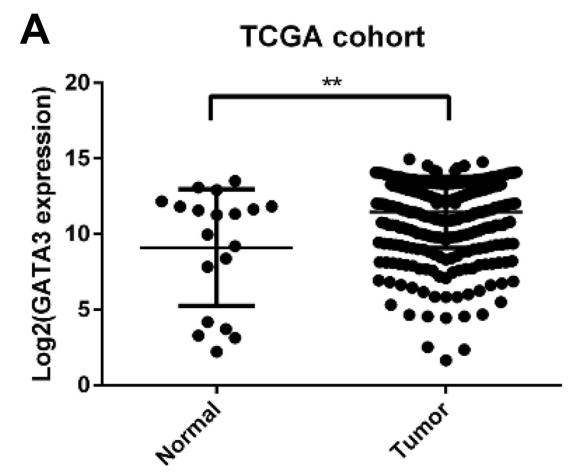

\section{The Correlation Between GATA3}

Expression and Clinicopathological Parameters in FFPE Cohort

The expression of GATA3 in 107 specimens from FFPE cohort was immunohistochemically investigated in the present study (Figure 2). GATA3 was positive in 94 of 107 $(87.9 \% ; 23.1+; 41.2+; 30.2+)$ primary tumors. The correlation between the expression levels of respective stains and clinicopathological parameters was subsequently evaluated (Table 1). There were no statistically significant differences between the GATA3 expression pattern and the age as well as gender. As for tumor grade, there were $79.3 \%$ (46/58) low-grade tumors were moderately or strongly positive for GATA3. However, as for high-grade patients, the positive rate was $51.0 \%(25 / 49)(P=0.002)$. Similarly, 55 of 71 (77.4\%) papillary carcinomas were moderately or strongly expressed GATA3, compared with 17 of 36 (47.2\%) nonpapillary carcinomas $(P=0.003)$. In contrast, significantly higher GATA3 expression was detected in patients diagnosed with TNM stage I or II $(P<0.001)$.

\section{The Correlation Between GATA3 Expression and Clinicopathological \\ Parameters in TCGA Cohort}

Three hundred and sixty-four bladder cancer cases from TCGA cohort with complete clinicopathological profile and follow-up records were split into high-expression and lowexpression group using the mean of normalized GATA3 expression as a cut-off value. The detailed results of clinicopathological differences by comparing two groups are summarized in Table 2. There were strong correlations between the status of GATA3 expression and tumor subtypes $(P=0.001)$, pathological grade $(P=0.057)$ as well as AJCC

\section{B}

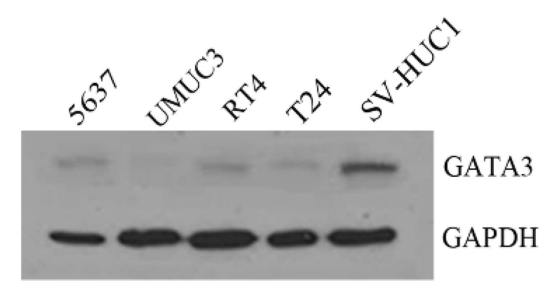

Figure I The GATA3 expression in bladder cancer. (A) mRNA level of GATA3 was analyzed using TCGA cohort containing 364 bladder cancer samples and 19 normal samples. (B) The protein expression level of GATA3 in bladder cancer cell lines compared with normal urothelial cell line SV-HUCI. Data are presented as the mean \pm standard deviation. $* * \mathrm{P}<0.01$. 


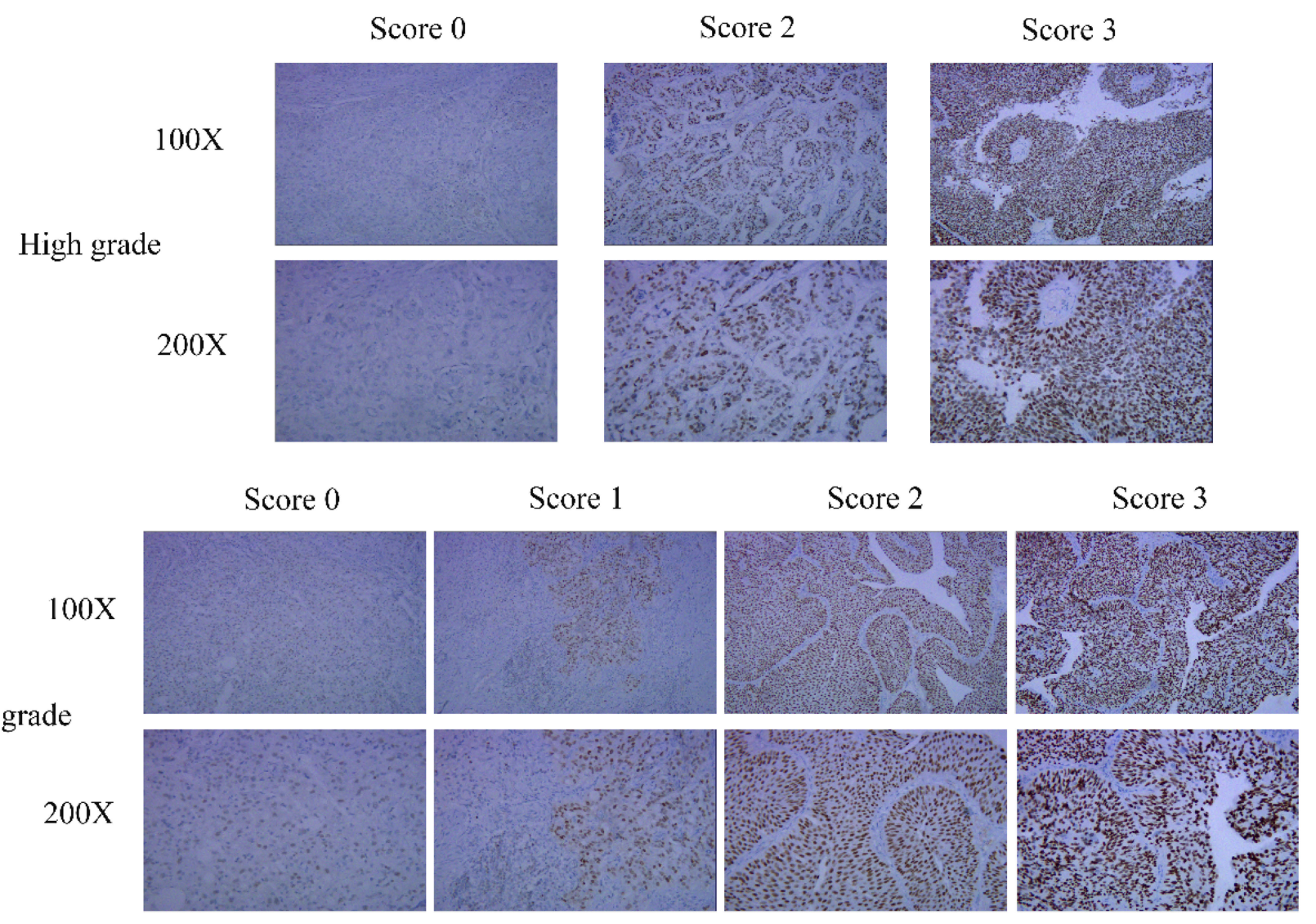

Figure 2 Immunohistochemistry analysis of GATA3 protein expression in low-grade and high-grade tissues. IHC Score in cancer tissues was shown.

stage $(P<0.001)$. However, no statistical differences were noted between GATA3 expression and tumor recurrence ( $P=010.413$ ). In addition, we divided all cases into two groups by tumor stage (pT2 vs pT3+4) and redefined the status of GATA3 expression in groups of different clinical stages (Table 3). There was no correlation of GATA3 expression with tumor recurrence $(P=0.952)$ but significant positive correlation with pathological grade $\left(R_{S}=0.388 ; P=0.022\right)$ and negative correlation with tumor subtypes $\left(R_{S}=-0.201\right.$; $P=0.001)$ in the patients of $\mathrm{pT} 2$ group. Nonetheless, patients in pT3+4 group only showed tumor subtypes $\left(R_{s}=0.217\right.$; $P=0.001)$ was significantly positive correlated to the GATA3 expression.

\section{The Association of GATA3 Expression to Survival Prognosis}

For survival analysis, Kaplan-Meier analysis coupled with Log-rank test revealed that patients with the decreased expression of GATA3 in TCGA cohort $(P=0.039)$ but the increased expression in FFPE cohort $(P<0.001)$ had shorter overall survival time. Next, multivariate analyses of Cox regression model were performed to show that age $(P<0.001$ in both cohort), clinical stage $(P=0.028$ in TCGA; $P=0.003$ in FFPE), tumor recurrence $(P<0.001$ in TCGA $)$ and low GATA3 mRNA expression $(P=0.035$ in TCGA) but high GATA3 expression $(P=0.014$ in FFPE) were significantly correlated to overall survival in patients with bladder cancer (Table 4) (Figure 3A and B). According to subgroup study of clinical stage, enforced expression of GATA3 served as an independent predictor of lower overall survival $(P=0.032)$ in patients with papillary bladder cancer (Figure 4A). Nevertheless, multivariate analyses $(P=0.255)$ revealed no correlation between the expression of GATA3 and overall survival of patients in non-papillary group (Figure 4B). Subgroup analyses in tumor grade showed high GATA3 $(P=0.041)$ independently predicted an unfavorable outcome for overall survival in high-grade tumors (Figure 4C), whereas not in low-grade tumors $(P=0.295)$ (Figure 4D). Additionally, strong expression of GATA3 was also suggested as an independent predictor of poor prognosis in muscle-invasive patients $(P=0.018)$ (Figure 3E). 
Table I The Relationship Between GATA3 and Clinicopathologic Characteristics in Patients with Bladder Cancer from FFPE Cohort

\begin{tabular}{|c|c|c|c|c|c|c|c|c|}
\hline \multirow[t]{2}{*}{ Parameter } & \multicolumn{6}{|c|}{ N Positivity } & \multirow[b]{2}{*}{$2+/ 3+(\%)$} & \multirow{2}{*}{$\begin{array}{l}\text { Fisher test ( } P \text { value) } \\
0 / 1+\text { vs } 2+/ 3+\end{array}$} \\
\hline & & 0 (\%) & $I+(\%)$ & $2+(\%)$ & $3+(\%)$ & $0 / 1+(\%)$ & & \\
\hline Age & & & & & & & & 0.630 \\
\hline$<65$ & 36 & $3(8.3)$ & $8(22.2)$ & 14 (38.9) & II (30.6) & II (30.6) & $25(69.4)$ & \\
\hline$\geq 65$ & 71 & $10(14.1)$ & $15(2 \mid .1)$ & $27(38.0)$ & $19(26.8)$ & $25(35.2)$ & $46(64.8)$ & \\
\hline Gender & & & & & & & & 0.574 \\
\hline Female & 15 & $2(13.3)$ & $4(26.6)$ & $7(46.7)$ & $2(13.3)$ & $6(40.0)$ & $9(60.0)$ & \\
\hline Male & 92 & II (I2.0) & $19(20.7)$ & $34(37.0)$ & $28(30.4)$ & $30(32.6)$ & $30(67.4)$ & \\
\hline Grade & & & & & & & & 0.002 \\
\hline Low & 58 & $7(12.1)$ & $5(8.6)$ & $26(44.8)$ & $20(34.5)$ & $12(20.7)$ & $46(79.3)$ & \\
\hline High & 49 & $6(12.2)$ & $18(36.7)$ & $15(30.6)$ & $10(20.4)$ & $24(49.0)$ & $25(51.0)$ & \\
\hline TNM Stage & & & & & & & & $<0.001$ \\
\hline I II & 72 & $2(2.8)$ & $9(12.5)$ & $33(45.8)$ & $28(38.9)$ & II (I5.3) & 61 (84.7) & \\
\hline III IV & 35 & II (3I.4) & $14(40.0)$ & $8(22.9)$ & $2(5.7)$ & $25(7 \mid .4)$ & $10(28.6)$ & \\
\hline Tumor Stage & & & & & & & & 0.026 \\
\hline NMIBC & 30 & $2(6.7)$ & $4(13.3)$ & 14 (46.7) & $10(33.3)$ & $6(20.0)$ & $24(80.0)$ & \\
\hline $\mathrm{pT}_{\mathrm{a}}$ & 17 & $2(11.8)$ & $2(11.8)$ & $6(35.3)$ & $7(4 \mid .2)$ & $4(23.5)$ & I3 (76.5) & \\
\hline $\mathrm{pT}_{1}$ & 13 & $0(0)$ & $2(15.4)$ & $8(61.5)$ & $3(23.1)$ & $2(15.4)$ & $2(84.6)$ & \\
\hline MIBC & 77 & II (I4.3) & $19(24.7)$ & $27(35.1)$ & $20(26.0)$ & $30(39.0)$ & $47(61.0)$ & \\
\hline $\mathrm{PT}_{2}$ & 49 & $3(6.1)$ & $4(8.2)$ & $23(46.9)$ & $19(38.8)$ & $7(14.3)$ & $42(85.7)$ & \\
\hline $\mathrm{PT}_{3}$ & 17 & $7(4 \mid .2)$ & $7(4 \mid .2)$ & $2(11.8)$ & I (5.9) & $14(82.4)$ & $3(17.6)$ & \\
\hline $\mathrm{PT}_{4}$ & 11 & I (9.1) & $8(72.7)$ & $2(18.2)$ & $0(0)$ & $9(81.8)$ & $2(18.2)$ & \\
\hline Lymph Node Involvement & & & & & & & & $<0.001$ \\
\hline $\mathrm{pN}_{0}$ & 50 & $2(4.0)$ & $4(8.0)$ & $24(48.0)$ & $20(40.0)$ & $6(12.0)$ & $44(88.0)$ & \\
\hline $\mathrm{pN}_{+}$ & 27 & $9(33.3)$ & $12(44.4)$ & $4(14.8)$ & $2(7.4)$ & $21(77.8)$ & $21(22.2)$ & \\
\hline Subtype & & & & & & & & 0.003 \\
\hline Papillary & 71 & $9(12.7)$ & $8(I 1.3)$ & $31(43.7)$ & $23(32.4)$ & 17 (23.9) & $54(76.1)$ & \\
\hline Non-Papillary & 36 & 4 (II.I) & $15(41.7)$ & $10(27.8)$ & $7(19.4)$ & $19(52.8)$ & 17 (47.2) & \\
\hline
\end{tabular}

\section{Validation of the GATA3 Expression Following Transfection}

Following the transfection of pcDNA3.1-GATA3 or mock, RT-qPCR was then conducted to detect the GATA3 expression in bladder cancer cell lines (T24 and UMUC3). The results suggested that GATA3 was strongly up-regulated in cells transfected with pcDNA3.1-GATA3 compared with cells transfected with mock (Figure 5A and B).

\section{GATA3 Has No Influence on the Apoptosis of Bladder Cancer Cells}

To access the biological activity of GATA3, flow cytometry was used to determine the apoptotic rate. After $48 \mathrm{~h}$, the experiment indicated that apoptotic rate in T24 and UMUC3 cells transfected with pcDNA3.1-GATA3 or mock was $2.75 \%$ vs $2.48 \%$ and $2.52 \%$ vs $2.45 \%$, respectively $(P=0.22$ in $\mathrm{T} 24$ and $P=0.31$ in UMUC3, Figure 6A). The result demonstrated that GATA3 has no influence on the apoptosis of bladder cancer.

\section{GATA3 Impairs G0/GI Cell Cycle Checkpoint}

The potential mechanism of GATA3 in bladder cancer was investigated by cell cycle distribution. In T24 cells, we found significant $\mathrm{G} 2 / \mathrm{M}$ phase arrest after transfected with pcDNA3.1- GATA3 (Figure 6B). Meanwhile, S phase was also found to be arrested in T24 cells overexpressing GATA3. However, GATA3 overexpression has no significant influence in cell phase in UMUC3 cells compared with mock cells (Figure 6C). The results revealed a potential role of GATA3 in cell cycle progression in T24 cells. 
Table 2 The Relationship Between the Differential Expression of GATA3 and Clinicopathologic Characteristics in TCGA Cohort

\begin{tabular}{|c|c|c|c|c|}
\hline \multirow[t]{2}{*}{ Parameter } & \multicolumn{4}{|c|}{ TCGA Cohort } \\
\hline & $\mathbf{N}$ & Low (139) (\%) & High (225) (\%) & $P$ \\
\hline Age & & & & 0.247 \\
\hline$<65$ & 134 & $46(34.3)$ & 88 (65.7) & \\
\hline$\geq 65$ & 230 & $93(40.4)$ & 137 (59.6) & \\
\hline Gender & & & & 0.145 \\
\hline Female & 92 & $41(44.6)$ & $51(55.4)$ & \\
\hline Male & 272 & $98(36.0)$ & $174(64.0)$ & \\
\hline Grade & & & & 0.057 \\
\hline Low & 20 & $0(0)$ & $20(100)$ & \\
\hline High & 344 & $139(40.4)$ & $205(59.6)$ & \\
\hline AJCC stage & & & & $<0.001$ \\
\hline $1 \sim 1 \mid$ & 124 & $39(31.5)$ & $85(68.5)$ & \\
\hline III IV & 240 & $100(4 \mid .7)$ & $140(58.3)$ & \\
\hline Subtype & & & & 0.001 \\
\hline Papillary & 116 & $22(19.0)$ & $94(81.0)$ & \\
\hline Non- Papillary & 248 & $117(47.2)$ & $|3|(52.8)$ & \\
\hline Recurrence & & & & \\
\hline No & 245 & $90(36.7)$ & $155(63.2)$ & 0.413 \\
\hline Yes & 119 & $49(4 \mid .2)$ & $70(58.8)$ & \\
\hline
\end{tabular}

\section{GATA3 Inhibits Proliferation in CCK-8 and EdU Assay}

To determine the effects of GATA3 overexpression on cell viability, T24 and UMUC3 proliferation were measured by the CCK-8 and EdU assay. As shown in Figure 7A, the result of CCK- 8 assay suggested that overexpression of GATA3 may attenuate cell proliferation. In T24 cells transfected with pcDNA3.1- GATA3, the proliferative ability was found significantly suppressed by $11.9 \%(P<0.01), 13.5 \%(P<0.001)$ and $13.6 \%(P<0.001)$, compared with mock cells. In UMUC3 cells, the cell proliferation rate was decreased by $11.6 \%(P<0.01), 15.2 \%(P<0.001)$ and $15.1 \%$ $(P<0.001)$ after transfecting with pcDNA3.1-GATA3. In addition, proliferative ability of the T24 and UMUC3 cells was also accessed by EdU staining (Figure 7B). Similar with the CCK-8 assay, the results of EdU assay revealed that the percentage of EdU-positive cells was decreased after GATA3 overexpression (Figure 7C), which indicated that the GATA3 may inhibit bladder cancer cell proliferation.

\section{Discussion}

Urothelial bladder cancer, one of the most common type of genitourinary cancers, is a chromosomally unstable tumor originating from the urothelial cells. ${ }^{34,35}$ The incidence and mortality of bladder cancer are rapidly increasing in the past few decades. In addition, this type of cancer posed a greater threat during the last three decades because few advances have been made in the development of new treatments and prevention options. Recently, the rapid development of techniques in the area of genome analysis has provided opportunities for personalized medicine. Therefore, molecular markers may serve as novel strategies for prediction of recurrence, prognosis and may provide new therapeutic applications for the patients of bladder cancer.

Reviewing several studies published in the last few decades, several molecular markers including GATA3, CK7, CK20, p63, S100P and high molecular weight cytokeratin (HMCK) were correlated with urothelial carcinoma of the urinary bladder. ${ }^{36-42}$ GATA3, one of the GATA family members, has emerged as a critical transcription

Table 3 The Relationship Between GATA3 and Clinicopathologic Characteristics in PT2 $N_{x} M_{x}$ vs pT3+4 N $M_{x}$ Patients with Bladder Cancer from TCGA Cohort

\begin{tabular}{|c|c|c|c|c|c|c|c|c|}
\hline \multirow[t]{2}{*}{ Parameter } & \multicolumn{4}{|c|}{ pT2 Patients } & \multicolumn{4}{|c|}{ pT3+4 Patients } \\
\hline & $\mathbf{N}$ & Low (42) (\%) & High (82) (\%) & $\mathbf{P}$ & $\mathbf{N}$ & Low (94) (\%) & High (146) (\%) & $\mathbf{P}$ \\
\hline Grade & & & & & & & 0.022 & 0.162 \\
\hline Low & 17 & $2(11.8)$ & $15(88.2)$ & & 3 & $0(0)$ & $3(100)$ & \\
\hline High & 107 & $40(37.4)$ & 67 (62.6) & & 237 & 94 (39.7) & $143(60.3)$ & \\
\hline Subtype & & & & 0.001 & & & & 0.001 \\
\hline Papillary & 58 & $8(13.8)$ & $50(86.2)$ & & 58 & $13(22.4)$ & $45(77.6)$ & \\
\hline Non- Papillary & 66 & $34(5 \mathrm{I} .5)$ & $32(48.5)$ & & 182 & 81 (44.5) & IOI (55.5) & \\
\hline \multicolumn{9}{|l|}{ Recurrence } \\
\hline No & 101 & $34(33.7)$ & $67(66.3)$ & 0.952 & 144 & $55(38.2)$ & $89(61.8)$ & 0.705 \\
\hline Yes & 23 & $8(34.8)$ & $15(65.2)$ & & 96 & $39(40.6)$ & $57(59.3)$ & \\
\hline
\end{tabular}


Table 4 Univariate and Multivariate Cox Regression Analysis for Overall Survival of Patients with Bladder Cancer

\begin{tabular}{|c|c|c|c|c|}
\hline \multirow[t]{2}{*}{ Parameter } & \multicolumn{2}{|l|}{ Univariate Analyses } & \multicolumn{2}{|c|}{ Multivariate Analyses } \\
\hline & HR (95\% Cl) & $P$ & HR (95\% Cl) & $P$ \\
\hline \multicolumn{5}{|l|}{ TCGA Cohort } \\
\hline $\begin{array}{l}\text { Age } \\
(<65 \text { vs } \geq 65)(134 \text { vs } 230)\end{array}$ & $1.032(1.016 \sim 1.048)$ & $<0.001$ & $2.136(1.465 \sim 3.115)$ & $<0.001$ \\
\hline $\begin{array}{l}\text { Gender } \\
\text { (Female vs Male) (92 vs 272) }\end{array}$ & $0.903(0.65|\sim| .252)$ & 0.540 & - & - \\
\hline $\begin{array}{l}\text { Grade } \\
\text { (Low vs High) }(20 \text { vs } 344)\end{array}$ & $2.905(0.7 \mid 9 \sim 11.743)$ & 0.135 & - & - \\
\hline $\begin{array}{l}\text { Subtype } \\
\text { (Papillary vs Non- Papillary) (I I6 vs 248) }\end{array}$ & $0.655(0.459 \sim 0.933)$ & 0.019 & $0.765(0.5 \mid 2 \sim 1.142)$ & 0.205 \\
\hline $\begin{array}{l}\text { AJCC stage } \\
\text { (II vs III IV) (I24 vs } 240)\end{array}$ & $2.225(1.536 \sim 3.224)$ & $<0.001$ & 1.574 (I.058 2.342) & 0.028 \\
\hline $\begin{array}{l}\text { Recurrence } \\
\text { (No vs Yes) ( } 245 \text { vs II9) }\end{array}$ & $2.247(1.635 \sim 3.088)$ & $<0.001$ & $2.080($ ( $.494 \sim 2.896)$ & $<0.001$ \\
\hline $\begin{array}{l}\text { GATA3 } \\
\text { (High vs Low) (225 vs 139) }\end{array}$ & $0.703(0.522 \sim 0.945)$ & 0.007 & $0.715(0.517 \sim 0.991)$ & 0.035 \\
\hline \multicolumn{5}{|l|}{ FFPE Cohort } \\
\hline $\begin{array}{l}\text { Age } \\
(<65 \text { vs } \geq 65)(36 \text { vs } 71)\end{array}$ & $7.100(2.193 \sim 22.989)$ & $<0.001$ & $8.240(2.484 \sim 27.336)$ & $<0.001$ \\
\hline $\begin{array}{l}\text { Gender } \\
\text { (Female vs Male) (15 vs 92) }\end{array}$ & $\begin{array}{l}0.676 \\
(0.311 \sim 1.467)\end{array}$ & 0.322 & - & - \\
\hline $\begin{array}{l}\text { Grade } \\
\text { (Low vs High) ( } 58 \text { vs } 49)\end{array}$ & $0.705(0.380 \sim 1.307)$ & 0.267 & - & - \\
\hline $\begin{array}{l}\text { Subtype } \\
\text { (Papillary vs Non- Papillary) (7I vs } 36 \text { ) }\end{array}$ & $1.966(1.061 \sim 3.642)$ & 0.032 & $\begin{array}{l}0.927 \\
(0.478 \sim 1.795)\end{array}$ & 0.465 \\
\hline $\begin{array}{l}\text { TNM stage } \\
\text { (II vs III } \sim \text { IV) }(72 \text { vs } 35)\end{array}$ & 3.357 (I.798 6.264) & $<0.001$ & $\begin{array}{l}2.94 \mathrm{I} \\
(1.453 \sim 5.954)\end{array}$ & 0.003 \\
\hline $\begin{array}{l}\text { GATA3 } \\
(0 / I+\text { vs } 2+/ 3+)(36 \text { vs } 7 I)\end{array}$ & $0.303(0.164 \sim 0.56 \mathrm{I})$ & $<0.001$ & $\begin{array}{l}0.419 \\
(0.209 \sim 0.840)\end{array}$ & 0.014 \\
\hline
\end{tabular}

factor in the development and differentiation of various tumor tissues. Higgins ${ }^{30}$ initially investigated that GATA3 were expressed in two-thirds of urothelial carcinomas, while there was absent in nonurothelial neoplasms except breast ductal carcinomas. For further study, an immunohistochemical analysis was performed for investigating the association between GATA3 and urothelial differentiation in a series of variants of the urothelial bladder carcinoma. In that research, the positivity rates of GATA3 for conventional urothelial carcinomas was $80 \%$, for urothelial carcinomas variants (micropapillary, plasmacytoid, nested, clear cell and microcystic) was $88 \%$, and for undifferentiated carcinomas (lymphoepitheliomalike carcinoma, small cell carcinoma and sarcomatoid carcinoma) was $28 \%{ }^{43}$ As for the prediction of clinical response to intravesical BCG therapy in bladder cancer, a low density of
GATA3 was observed as one of the useful indicators for identifying BCG failure. ${ }^{44}$ Pichler et $\mathrm{al}^{45}$ supposed that GATA3, served as a Th2-promoting factor, may contribute to the BCG success by triggering Th1-type immune responses. Additionally, according to a recent study published by Wang, ${ }^{46}$ low GATA3 IHC staining was correlated with worse recurrence-free survival in bladder cancer patients.

In the present study, using 364 bladder cancer cases and 19 non-cancerous tissues in TCGA database, GATA3 mRNA expression was found significantly higher in primary bladder cancer than in benign urothelial epithelium. To confirm the differential expression of GATA3 in tumor and normal cells, we then examined the protein expression level in human bladder cancer cell lines. Nonetheless, the Western blot analysis revealed that GATA3 expression at 

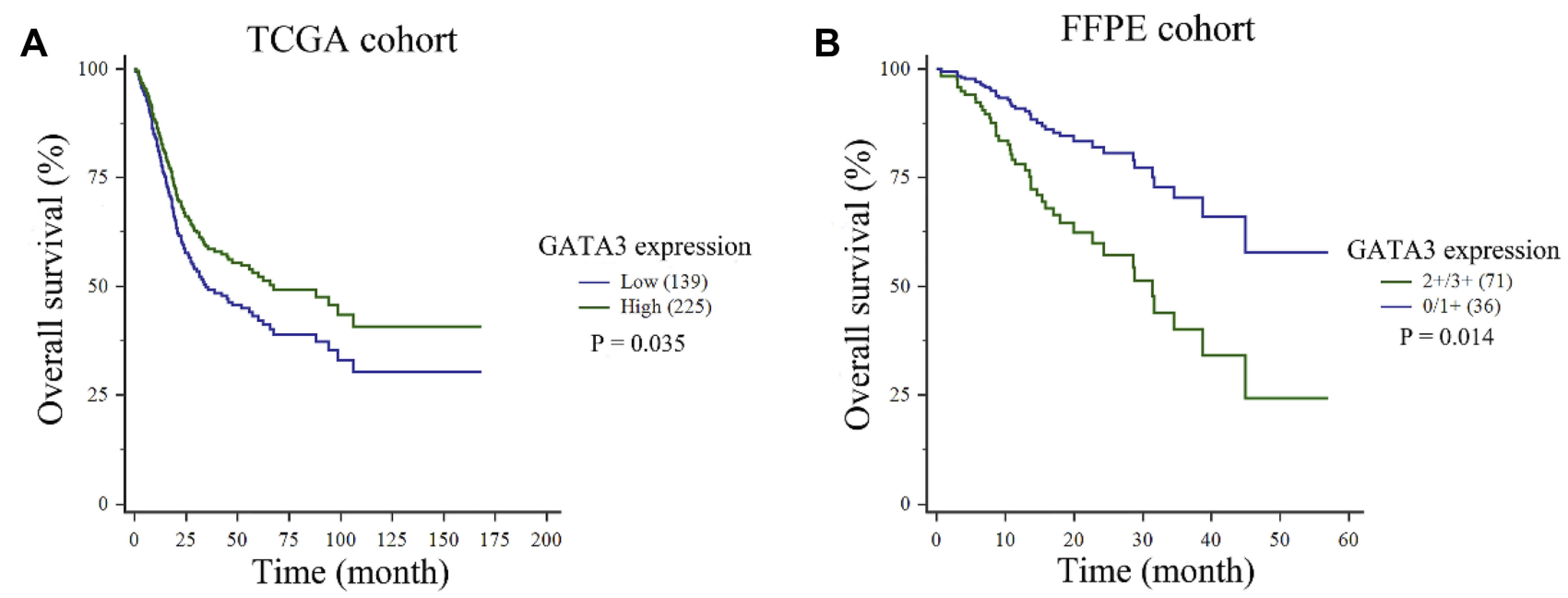

Figure 3 Multivariate Cox regression was presented according to GATA3 expression. (A) Low expression of GATA3 mRNA predicted worse prognosis in patients with bladder cancer in TCGA cohort. (B) GATA3 IHC score of 2+/3+ predicted worse prognosis in patients with bladder cancer in FFPE cohort.

the protein level in 5637, UMUC3, RT4 and T24 was significantly decreased compared with the SV-HUC1 human normal urothelial cell line. These results indicated that GATA3 expression may be mediated through posttranscriptional modification, which may include altered transcription efficiency, mRNA stability, protein degradation rate or other mechanisms.

Furthermore, we detected an association between GATA3 expression and clinicopathological characteristics of bladder cancer patients based on TCGA and FFPE cohort. The results obtained in the present study indicated that GATA3 expression was significantly correlated with tumor subtypes ( $P=0.001$ in TCGA; $P=0.004$ in FFPE), clinical stage $(P<0.001$ in TCGA; $P<0.001$ in FFPE $)$ and tumor grade $(P=0.057$ in TCGA; $P=0.002$ in FFPE). In addition, Kaplan-Meier curves and Cox regression model in TCGA cohort showed that the prognosis of GATA3-deficient patients was predominantly worse than that of strong GATA3 patients. Interestingly, multivariate analysis performed with the Cox model in FFPE cohort demonstrated that high GATA3 was an independent predictor for patients with poor prognosis. The result of the present study in FFPE cohort was consistent with previous experimental research of immunohistochemically stained for GATA3 in urothelial neoplasm. ${ }^{31}$ However, Kamel and colleagues ${ }^{47}$ reported that down-regulated GATA3 expression could accurately predict progression in NMIBC. Whatever the low expression in mRNA level or high expression in protein level, it is confirmed that GATA3 plays a critical role in independently predicting the overall survival of bladder cancer patients. For the further subgroup analysis in FFPE cohort, GATA3 positive predicted a poor prognosis in patients with papillary bladder cancer but not in non-papillary patients. In addition, the present research asserted that the overexpression of GATA3 was closely associated with a long-term unfavorable outcome in high grade patients but not in low grades. Moreover, we discovered that strong GATA3 was also an independent prognostic factor for patients with muscleinvasive bladder cancer. Nonetheless, because of the lack of non-muscle invasive patients, we did not perform the Cox regression in these patients for subgroup analysis.

Based on the studies of the expression differences and clinical significance of GATA3 in bladder cancer, we further detected the potential functions of this important biomarker using cell apoptosis, proliferation and cycle assays. The results of cell apoptosis assay in T24 and UMUC3 cells indicated that the upregulation of GATA3 had no significant influence on cell apoptosis. Moreover, EdU and CCK-8 assay performed in the present study revealed that overexpression of GATA3 inhibited the process of T24 and UMUC3 cells proliferation, which indicated that GATA3 may be involved into bladder cancer cell tumorigenesis and development. Additionally, we identified that over-expressing GATA3 could arrest the cell cycle of G2/M and S phase in T24 cells, whereas GATA3 in UMUC3 cells has no influence on this process. Therefore, the biologic function of GATA3 in bladder cancer still needs further study.

In conclusion, we observed a strong association between GATA3 expression and clinical characteristics based on TCGA project and FFPE cohort. Kaplan-Meier 

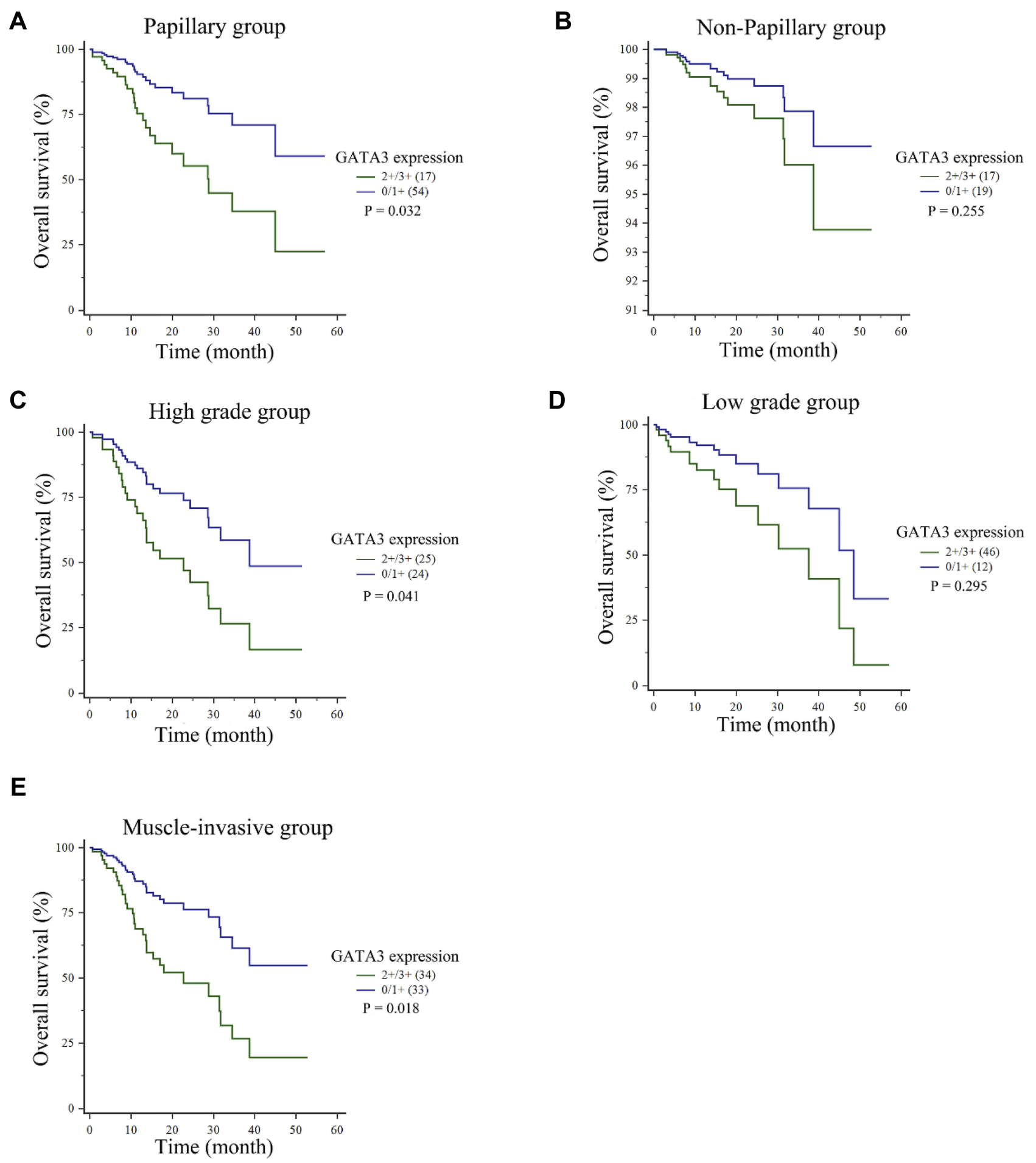

Figure 4 (A, B) GATA3 IHC score of $2+13+$ served as an independent predictor of lower overall survival in patients with papillary bladder cancer, whereas not in nonpapillary. (C, D) GATA3 IHC score of 2+/3+ independently predicted an unfavorable outcome for overall survival in high-grade tumors, whereas not in low-grade tumors. (E) GATA3 IHC score of $2+/ 3+$ was suggested as an independent predictor of poor prognosis in muscle-invasive patients.

and Cox regression analysis demonstrated that low GATA3 mRNA expression or high GATA3 expression at protein level predicted a shorter survival time and was identified as an independent prognostic biomarker for bladder cancer patients. Taken together, the present research suggested GATA3 served as a potential molecular marker for predicting prognosis in bladder cancer patients, especially in high grade/papillary/muscle invasive bladder 

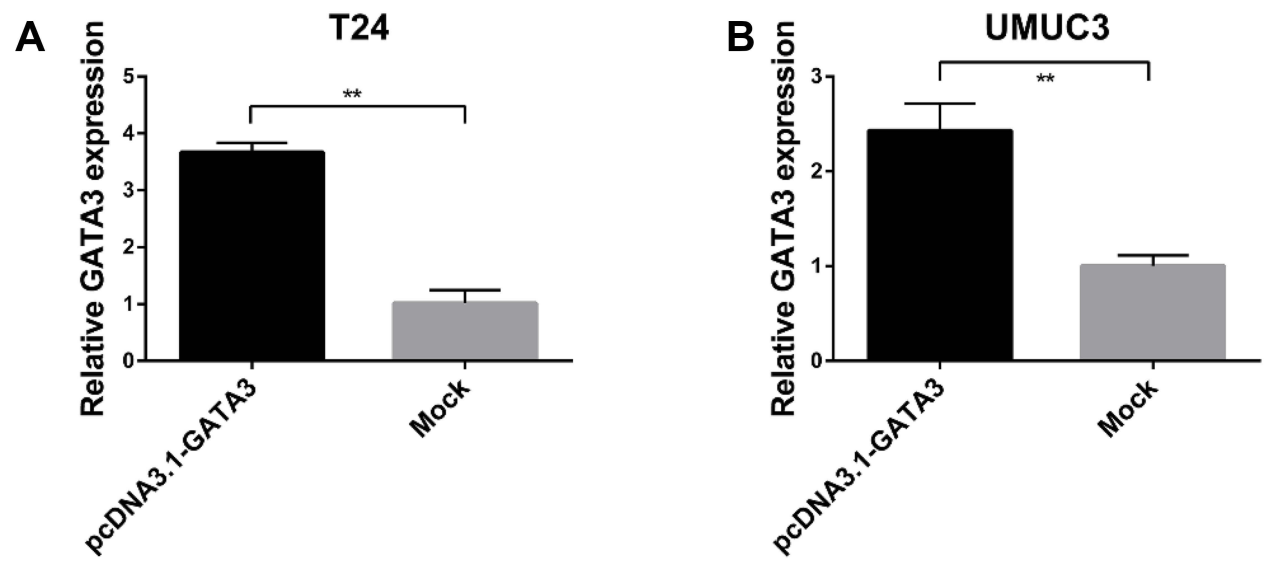

Figure 5 (A) Relative expression of GATA3 in T24 cells after transfection. (B) Relative expression of GATA3 in UMUC3 cells after transfection. Data are presented as the mean \pm standard deviation. $* * \mathrm{P}<0.01$.

A
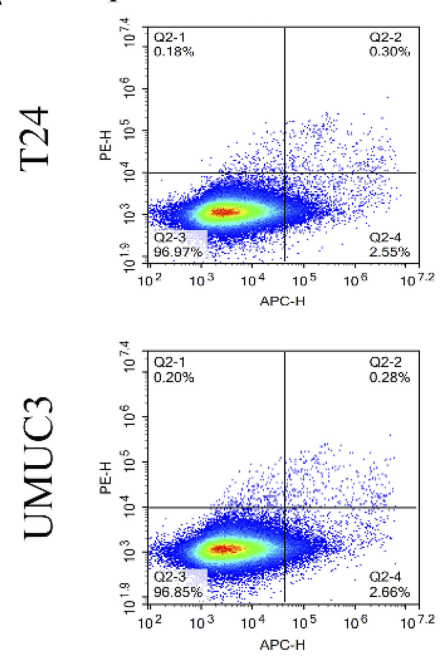

B

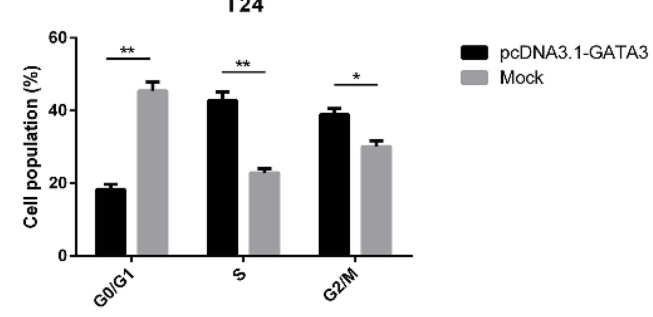

C

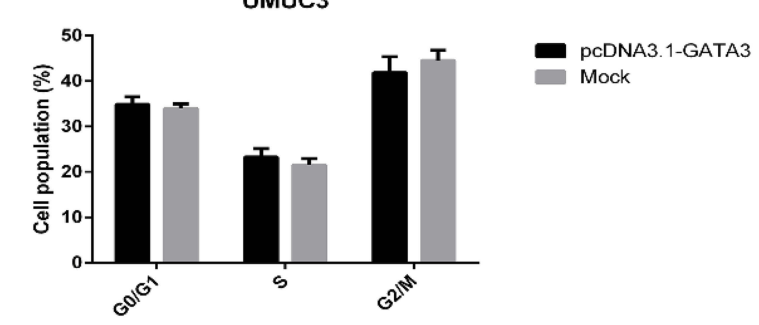

Mock
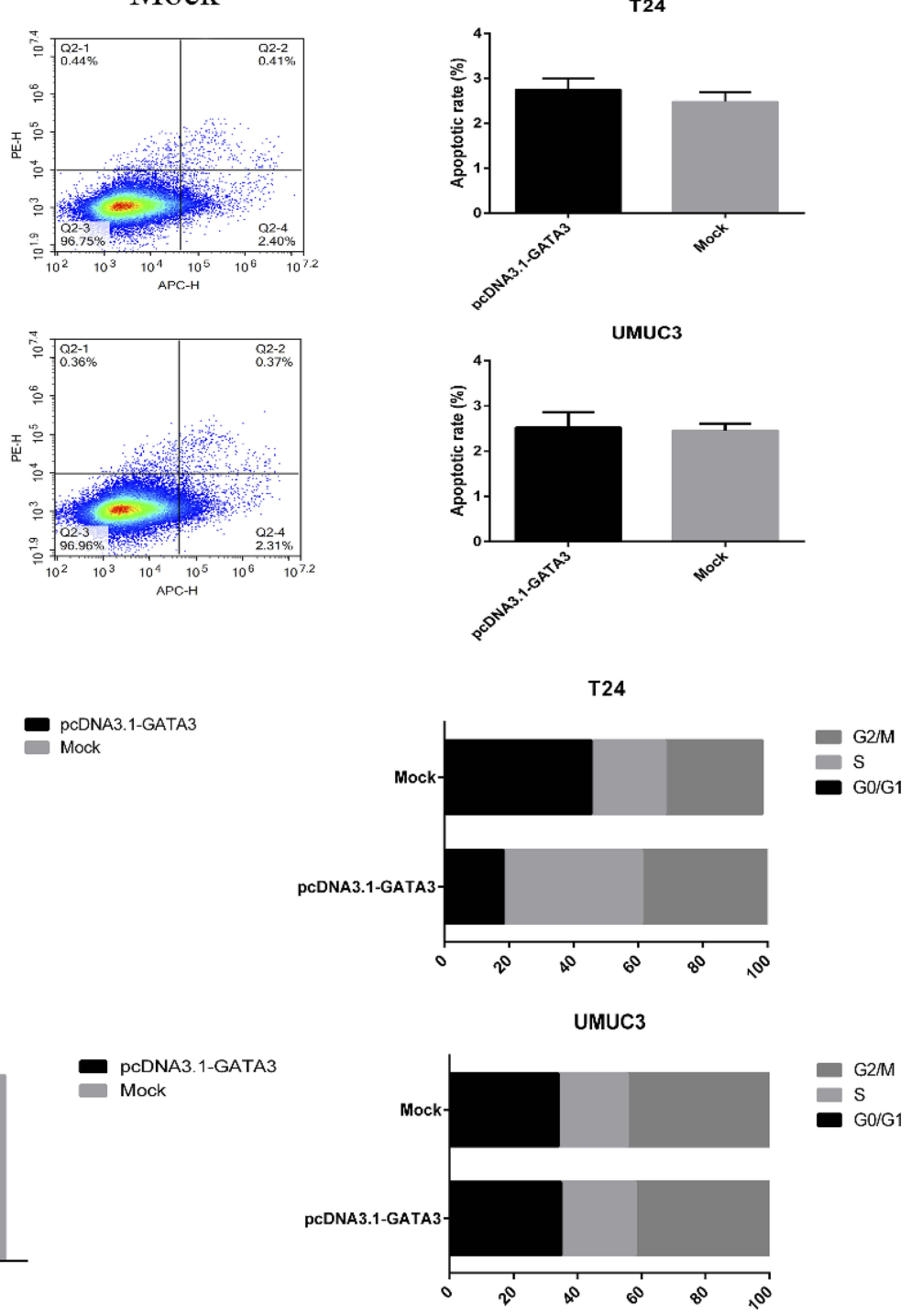

Figure 6 Cell apoptosis and cycle assays in T24 and UMUC3 cells. (A) Flow cytometric analysis of apoptosis. GATA3 has no influence on the apoptosis of T24 and UMUC3 cell lines. (B) Significant G2/M and S phase arrest in GATA3-overexpression T24 cells. (C) GATA3 overexpression has no significant influence in cell phase in UMUC3 cells. Data are presented as the mean \pm standard deviation. $* \mathrm{P}<0.05 ; * * \mathrm{P}<0.01$. 


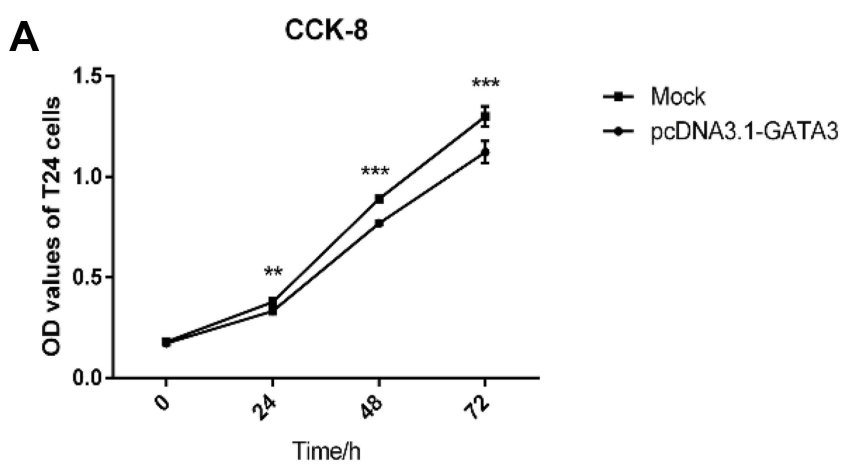

T24

B
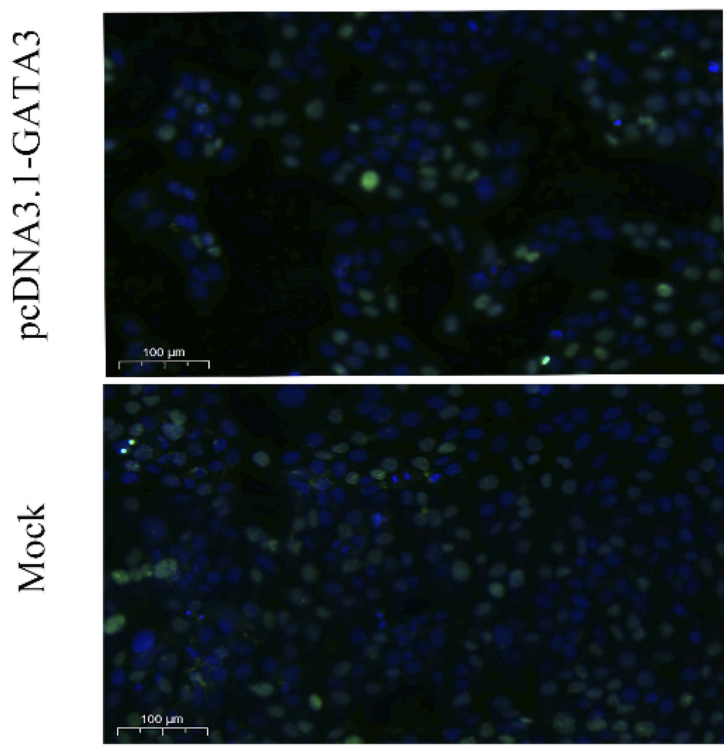

T24

C

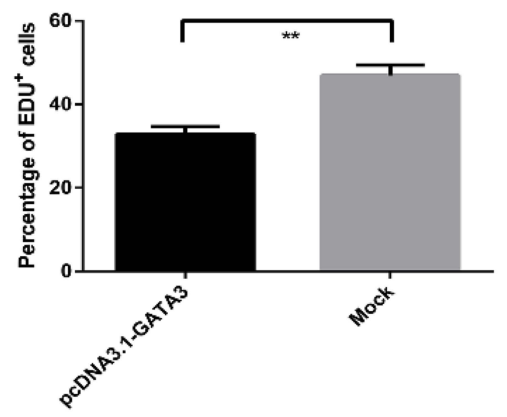

CCK-8

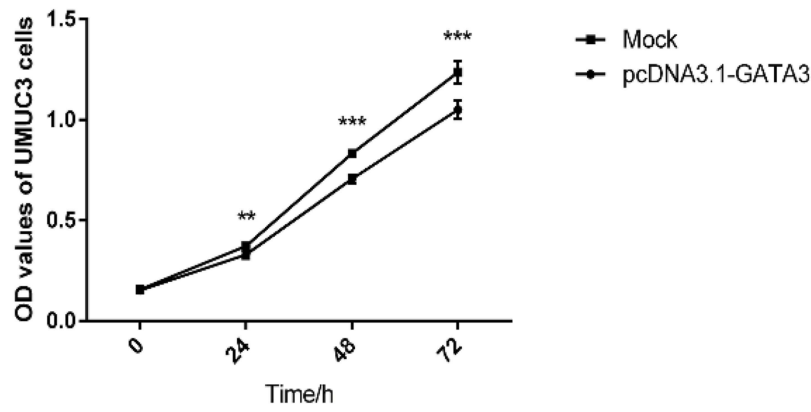

UMUC3
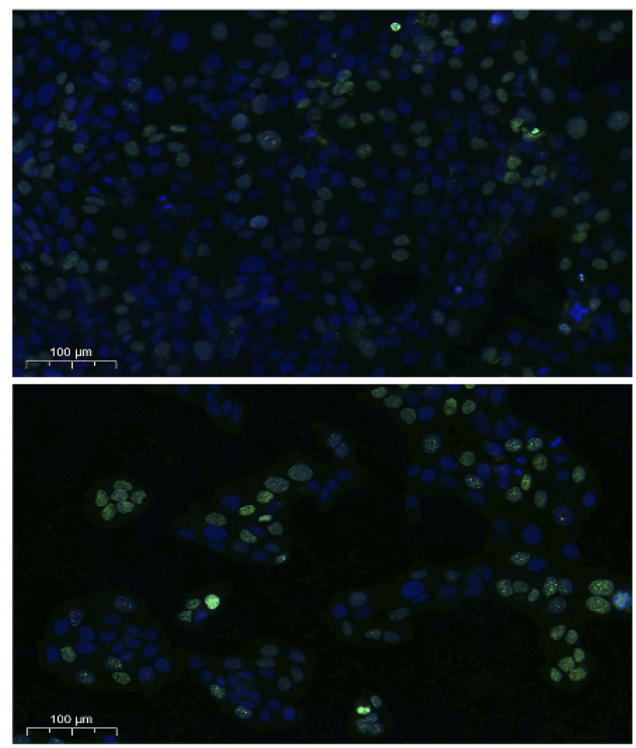

UMUC3

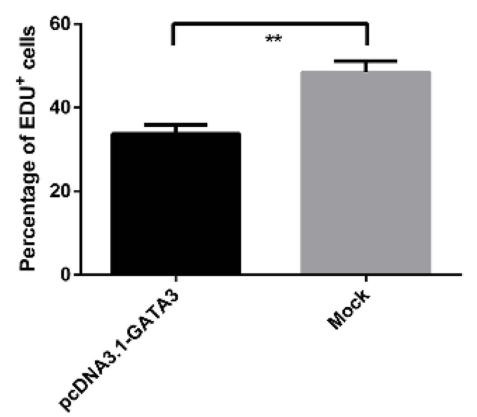

Figure 7 Cell proliferation assays in T24 and UMUC3 cells. (A) CCK-8 assay of T24 and UMUC3 cells transfected with pcDNA-3.1-GATA3 or mock. (B and C) EdU assay of T24 and UMUC3 cells transfected with pCDNA-3.I-GATA3 or mock. Data are presented as the mean \pm standard deviation. $* * \mathrm{P}<0.01 ; * * * \mathrm{P}<0.001$.

cancer. Whether further studies of GATA3 are still necessary to identify its biologic functions in bladder cancer.

\section{Ethics Approval and Consent to Participate}

All procedures conducted in this study were in compliance with the Declaration of Helsinki and obtained the appropriate approval by the Ethics Committee of the
Institutional Ethical Review Board of The Second Affiliated Hospital of Soochow University. Also, all patients have signed a consent statement.

\section{Acknowledgments}

This study was supported by the Youth Excellence Projects of CNNC (No.2018-272-4), Youth Workers Pre-Research Fund Project of the Second Affiliated Hospital of Soochow 
University (No. SDFEYQN1713), the Natural Science Foundation of Jiangsu Province (No. BK20160339), the Science and Technology Projects Foundation of Suzhou City (No. SYS201547) and the Natural Science Foundation of Suzhou University (No. SDY2015A17).

\section{Author Contributions}

All authors contributed to data analysis, drafting or revising the article, gave final approval of the version to be published, and agree to be accountable for all aspects of the work.

\section{Disclosure}

The authors report no conflicts of interest in this work.

\section{References}

1. Bray F, Ferlay J, Soerjomataram I, Siegel RL, Torre LA, Jemal A. Global cancer statistics 2018: GLOBOCAN estimates of incidence and mortality worldwide for 36 cancers in 185 countries. CA Cancer J Clin. 2018;68(6):394-424. doi:10.3322/caac.v68.6

2. Botteman MF, Pashos CL, Redaelli A, Laskin B, Hauser R. The health economics of bladder cancer: a comprehensive review of the published literature. Pharmacoeconomics. 2003;21(18):1315-1330. doi:10.1007/BF03262330

3. Fajkovic H, Halpern JA, Cha EK, et al. Impact of gender on bladder cancer incidence, staging, and prognosis. World J Urol. 2011;29 (4):457-463. doi:10.1007/s00345-011-0709-9

4. Antoni S, Ferlay J, Soerjomataram I, Znaor A, Jemal A, Bray F. Bladder cancer incidence and mortality: a global overview and recent trends. Eur Urol. 2017;71(1):96-108. doi:10.1016/j.eururo.2016.06.010

5. Shariat SF, Karakiewicz PI, Palapattu GS, et al. Outcomes of radical cystectomy for transitional cell carcinoma of the bladder: a contemporary series from the Bladder Cancer Research Consortium. J Urol. 2006;176(6 Pt 1):2414-2422; discussion 2422. doi:10.1016/j.juro.2006.08.004

6. Madersbacher S, Hochreiter W, Burkhard F, et al. Radical cystectomy for bladder cancer today-a homogeneous series without neoadjuvant therapy. J Clin Oncol. 2003;21(4):690-696. doi:10.1200/JCO.2003.05.101

7. Racioppi M, D'Agostino D, Totaro A, et al. Value of current chemotherapy and surgery in advanced and metastatic bladder cancer. Urol Int. 2012;88(3):249-258. doi:10.1159/000335556

8. Babjuk M, Burger M, Zigeuner R, et al. EAU guidelines on non-muscleinvasive urothelial carcinoma of the bladder: update 2013. Eur Urol. 2013;64(4):639-653. doi:10.1016/j.eururo.2013.06.003

9. Enfortumab vedotin checks urothelial cancer. Cancer Discov. 2019;9 (10):OF1. doi:10.1158/2159-8290.CD-NB2019-104

10. Rosenberg JE, O'Donnell PH, Balar AV, et al. Pivotal trial of enfortumab vedotin in urothelial carcinoma after platinum and anti-programmed death 1/programmed death ligand 1 therapy. J Clin Oncol. 2019;37(29):2592-2600. doi:10.1200/JCO.19.01140

11. Targeting Nectin-4 in bladder cancer. Cancer Discov. 2017;7(8):OF3. doi:10.1158/2159-8290.CD-NB2017-095

12. Wang L, Gong Y, Saci A, et al. Fibroblast growth factor receptor 3 alterations and response to PD-1/PD-L1 blockade in patients with metastatic urothelial cancer. Eur Urol. 2019;76(5):599-603. doi:10.1016/j.eururo.2019.06.025

13. Hosoya T, Maillard I, Engel JD. From the cradle to the grave: activities of GATA-3 throughout T-cell development and differentiation. Immunol Rev. 2010;238(1):110-125. doi:10.1111/ imr.2010.238.issue-1
14. Ho IC, Vorhees $\mathrm{P}$, Marin $\mathrm{N}$, et al. Human GATA-3: a lineage-restricted transcription factor that regulates the expression of the T cell receptor alpha gene. EMBO J. 1991;10(5):1187-1192. doi:10.1002/embj.1991.10.issue-5

15. Ko LJ, Yamamoto M, Leonard MW, George KM, Ting P, Engel JD. Murine and human T-lymphocyte GATA-3 factors mediate transcription through a cis-regulatory element within the human T-cell receptor delta gene enhancer. Mol Cell Biol. 1991;11(5):2778. doi:10.1128/ MCB.11.5.2778

16. Shahi P, Wang CY, Chou J, et al. GATA3 targets semaphorin 3B in mammary epithelial cells to suppress breast cancer progression and metastasis. Oncogene. 2017;36(40):5567-5575. doi:10.1038/ onc. 2017.165

17. Kouros-Mehr H, Kim JW, Bechis SK, Werb Z. GATA-3 and the regulation of the mammary luminal cell fate. Curr Opin Cell Biol. 2008;20(2):164-170. doi:10.1016/j.ceb.2008.02.003

18. Asselin-Labat ML, Sutherland KD, Barker H, et al. Gata-3 is an essential regulator of mammary-gland morphogenesis and luminal-cell differentiation. Nat Cell Biol. 2007;9(2):201-209. doi:10.1038/ncb1530

19. Grote D, Souabni A, Busslinger M, Pax BM. 2/8-regulated Gata 3 expression is necessary for morphogenesis and guidance of the nephric duct in the developing kidney. Development. 2006;133(1):53-61. doi: $10.1242 /$ dev.02184

20. Liao MH, Lin PI, Ho WP, Chan WP, Chen TL, Chen RM. Participation of GATA-3 in regulation of bone healing through transcriptional upregulation of bcl-xL expression. Exp Mol Med. 2017;49 (11):e398. doi:10.1038/emm.2017.182

21. Tong Q, Dalgin G, Xu H, CN T, Leiden JM, Hotamisligil GS. Function of GATA transcription factors in preadipocyte-adipocyte transition. Science. 2000;290(5489):134-138. doi:10.1126/science.290.5489.134

22. Pai SY, Truitt ML, Ting CN, Leiden JM, Glimcher LH, Ho IC. Critical roles for transcription factor GATA-3 in thymocyte development. Immunity. 2003;19(6):863-875. doi:10.1016/S10747613(03)00328-5

23. Grigorieva IV, Mirczuk S, Gaynor KU, et al. Gata3-deficient mice develop parathyroid abnormalities due to dysregulation of the parathyroid-specific transcription factor Gcm2. J Clin Invest. 2010;120(6):2144-2155. doi:10.1172/JCI42021

24. Singh PNP, Yadav US, Azad K, Goswami P, Kinare V, Bandyopadhyay A. NFIA and GATA3 are crucial regulators of embryonic articular cartilage differentiation. Development. 2018;145(2). doi:10.1242/dev.156554

25. Kaufman CK, Zhou P, Pasolli HA, et al. GATA-3: an unexpected regulator of cell lineage determination in skin. Genes Dev. 2003;17 (17):2108-2122. doi:10.1101/gad.1115203

26. Kurek D, Garinis GA, van Doorninck JH, van der Wees J, Grosveld FG. Transcriptome and phenotypic analysis reveals Gata3-dependent signalling pathways in murine hair follicles. Development. 2007;134(2):261-272. doi:10.1242/dev.02721

27. Dydensborg AB, Rose AA, Wilson BJ, et al. GATA3 inhibits breast cancer growth and pulmonary breast cancer metastasis. Oncogene. 2009;28(29):2634-2642. doi:10.1038/onc.2009.126

28. Fang SH, Chen Y, Weigel RJ. GATA-3 as a marker of hormone response in breast cancer. J Surg Res. 2009;157(2):290-295. doi:10.1016/j.jss.2008.07.015

29. Hoch RV, Thompson DA, Baker RJ, Weigel RJ. GATA-3 is expressed in association with estrogen receptor in breast cancer. Int $J$ Cancer. 1999;84(2):122-128. doi:10.1002/(ISSN)1097-0215

30. Higgins JP, Kaygusuz G, Wang L, et al. Placental S100 (S100P) and GATA3: markers for transitional epithelium and urothelial carcinoma discovered by complementary DNA microarray. Am J Surg Pathol. 2007;31(5):673-680. doi:10.1097/01.pas.0000213438.01278.5f

31. Miyamoto H, Izumi K, Yao JL, et al. GATA binding protein 3 is down-regulated in bladder cancer yet strong expression is an independent predictor of poor prognosis in invasive tumor. Hum Pathol. 2012;43(11):2033-2040. doi:10.1016/j.humpath.2012.02.011 
32. Li Y, Ishiguro H, Kawahara T, Kashiwagi E, Izumi K, Miyamoto H. Loss of GATA3 in bladder cancer promotes cell migration and invasion. Cancer Biol Ther. 2014;15(4):428-435. doi:10.4161/cbt.27631

33. Eble JN, Sauter G, Epstein JI, Sesterhen IA. World Health Organization Classification Fo Tumour. Pathology and Genetics of Tumours of the Urinary System and Male Genital Organs. Vol. 1; 2004. Available from: https://www.researchgate.net/publication/ 235437765_World_Health_Organization_Classification_fo_Tumour_ Pathology_and_Genetics_of_Tumours_of_the_Urinary_System_and_Male_Genital_Organs. Accessed January 24, 2020.

34. Sandberg AA. Cytogenetics and molecular genetics of bladder cancer: a personal view. Am J Med Genet. 2002;115(3):173-182. doi:10.1002/ajmg.10693

35. Wu XR. Urothelial tumorigenesis: a tale of divergent pathways. Nat Rev Cancer. 2005;5(9):713-725. doi:10.1038/nrc1697

36. Bassily NH, Vallorosi CJ, Akdas G, Montie JE, Rubin MA. Coordinate expression of cytokeratins 7 and 20 in prostate adenocarcinoma and bladder urothelial carcinoma. Am $J$ Clin Pathol. 2000;113(3):383-388. doi:10.1309/G1RA-EU9X-X6VV-3W79

37. Harnden P, Cytokeratin SJ. 14 as a marker of squamous differentiation in transitional cell carcinomas. J Clin Pathol. 1997;50 (12):1032-1033. doi:10.1136/jcp.50.12.1032

38. Comperat E, Camparo P, Haus R, et al. Immunohistochemical expression of p63, p53 and MIB-1 in urinary bladder carcinoma. A tissue microarray study of 158 cases. Virchows Arch. 2006;448(3):319-324. doi:10.1007/s00428-005-0092-2

39. Chu PG, Weiss LM. Keratin expression in human tissues and neoplasms. Histopathology. 2002;40(5):403-439. doi:10.1046/j.1365-2559.2002.01 387.x

40. Huang HY, Shariat SF, Sun TT, et al. Persistent uroplakin expression in advanced urothelial carcinomas: implications in urothelial tumor progression and clinical outcome. Hum Pathol. 2007;38(11):1703-1713. doi:10.1016/j.humpath.2007.04.003
41. Moll R, Laufer J, Wu XR, Sun TT. [Uroplakin III, a specific membrane protein of urothelial umbrella cells, as a histological markers for metastatic transitional cell carcinomas]. Verh Dtsch Ges Pathol. 1993;77:260-265.

42. Kaufmann O, Fietze E, Mengs J, Dietel M. Value of p63 and cytokeratin $5 / 6$ as immunohistochemical markers for the differential diagnosis of poorly differentiated and undifferentiated carcinomas. Am J Clin Pathol. 2001;116(6):823-830. doi:10.1309/21TW-2NDGJRK4-PFJX

43. Paner GP, Annaiah C, Gulmann C, et al. Immunohistochemical evaluation of novel and traditional markers associated with urothelial differentiation in a spectrum of variants of urothelial carcinoma of the urinary bladder. Hum Pathol. 2014;45(7):1473-1482. doi:10.1016/j. humpath.2014.02.024

44. Pichler R, Fritz J, Zavadil C, Schafer G, Culig Z, Brunner A. Tumorinfiltrating immune cell subpopulations influence the oncologic outcome after intravesical Bacillus Calmette-Guerin therapy in bladder cancer. Oncotarget. 2016;7(26):39916-39930. doi:10.18632/oncotarget.9537

45. Pichler R, Gruenbacher G, Culig Z, et al. Intratumoral Th2 predisposition combines with an increased Th1 functional phenotype in clinical response to intravesical $\mathrm{BCG}$ in bladder cancer. Cancer Immunol Immunother. 2017;66(4):427-440. doi:10.1007/s00262-016-1945-Z

46. Wang CC, Tsai YC, Jeng YM. Biological significance of GATA3, cytokeratin 20, cytokeratin $5 / 6$ and p53 expression in muscle-invasive bladder cancer. PLoS One. 2019;14(8):e0221785. doi:10.1371/journal.pone.0221785

47. Kamel NA, Abdelzaher E, Elgebaly O, Ibrahim SA. Reduced expression of GATA3 predicts progression in non-muscle invasive urothelial carcinoma of the urinary bladder. J Histotechnol. 2019;1-8. doi: $10.1080 / 01478885.2019 .1667126$

\section{Publish your work in this journal}

OncoTargets and Therapy is an international, peer-reviewed, open access journal focusing on the pathological basis of all cancers, potential targets for therapy and treatment protocols employed to improve the management of cancer patients. The journal also focuses on the impact of management programs and new therapeutic agents and protocols on patient perspectives such as quality of life, adherence and satisfaction. The manuscript management system is completely online and includes a very quick and fair peer-review system, which is all easy to use. Visit http://www.dovepress.com/ testimonials.php to read real quotes from published authors. 